\title{
Correction to: Lentinula edodes as a Source of Bioelements Released Into Artificial Digestive Juices and Potential Anti-inflammatory Material
}

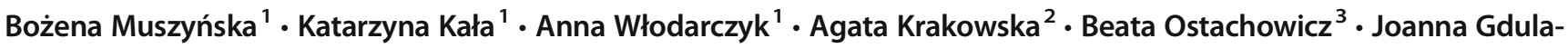 \\ Argasińska $^{4} \cdot$ Piotr Suchocki ${ }^{5}$
}

Published online: 24 July 2019

(C) Springer Science+Business Media, LLC, part of Springer Nature 2019

\section{Correction to: Biol Trace Elem Res}

https://doi.org/10.1007/s12011-019-01782-8

The original version of this article unfortunately contained a mistake. Figure 1 is in a wrong way exported to Pdf File (is in black color). The correct figure is shown below and in the current version.

Publisher's Note Springer Nature remains neutral with regard to jurisdictional claims in published maps and institutional affiliations.

The online version of the original article can be found at https://oi.org/ 10.1007/s12011-019-01782-8

Bożena Muszyńska

muchon@poczta.fm; bozena.muszynska@uj.edu.pl

1 Department of Pharmaceutical Botany, Faculty of Pharmacy, Jagiellonian University Medical College, Medyczna 9, 30-688 Krakow, Poland

2 Department of Inorganic and Analytical Chemistry, Faculty of Pharmacy, Jagiellonian University Medical College, Medyczna 9, 30-688 Krakow, Poland

3 Faculty of Physics and Applied Computer Sciences, AGH University of Science and Technology, Mickiewicza 30, 30-059 Krakow, Poland

4 Department of Radioligands, Faculty of Pharmacy, Jagiellonian University Medical College, Medyczna 9, 30-688 Krakow, Poland

5 Department of Bioanalysis and Drug Analysis, Faculty of Pharmacy, Medical University of Warsaw, Banacha 1, 02-097 Warsaw, Poland 

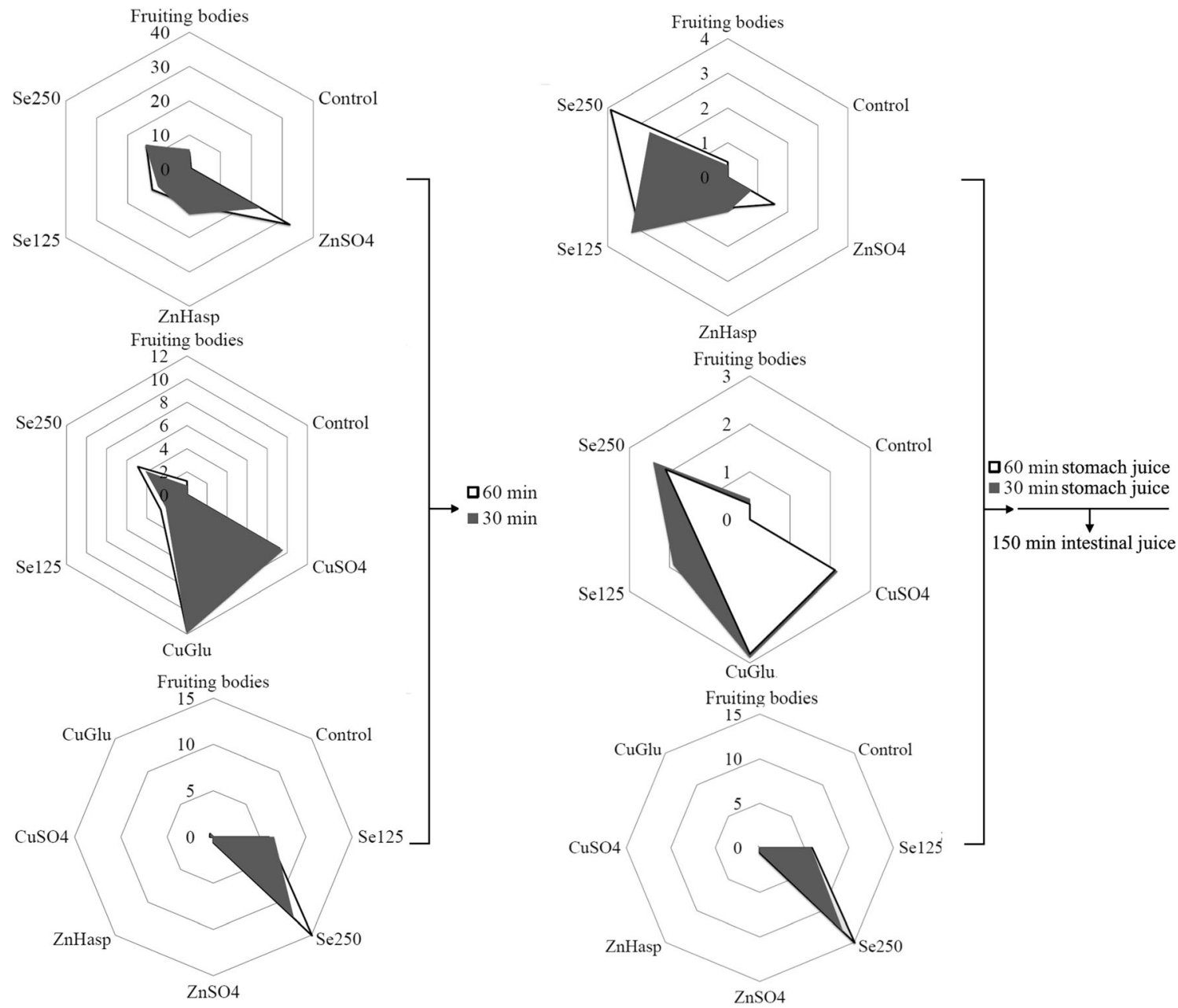